\title{
Assessment of Knowledge, Attitude and Practice of Emergency Contraceptive Pills among Medical and Paramedical Students
}

\author{
Bindu Malla ${ }^{1}$, Komal Malla ${ }^{2}$, Madan Sigdel ${ }^{1}$, Sanjeev Guragain ${ }^{1}$, Rajesh Kumar Yadav ${ }^{1}$, Sabita \\ Paudel $^{1}$, Bijay Aryal ${ }^{1}$
}

\begin{abstract}
Emergency contraceptive pill (ECP) is also called as morning after pill which is indicated after unprotected coitus, sexual abuse and nonuse of regular contraception to avoid unwanted pregnancy. The present study was conducted to evaluate the knowledge, attitude and current use of emergency contraceptive pill among the medical and paramedical students. Institution based cross- sectional descriptive study was conducted at Gandaki medical college and The School of Health and Allied sciences from August 2015-Janawary 2016.Data was collected using structured questionnaire and analyzed using Microsoft excel 2007. Out of 181 respondents $40.9 \%$ were male and $59.1 \%$ were female students. $91.2 \%$ respondents were from urban area and $86.2 \%$ were Hindu. As compared to female students, male students have more knowledge about the ECPs. However, female students were more correct than male students regarding the proper administration time of ECP. Although recipients have positive attitude regarding ECPs, majority of them believed that ECPs have harmful effects to the body. Mainly due to the humiliation and lack of proper knowledge, male respondents and female respondents respectively felt challenges to use ECPs. It is concluded the misinformation regarding ECPs is high among the respondents. Therefore, effective awareness program should be lunched to educate them regarding the ECPs and to protect young females from the risk of unsafe abortion.

Key words: Emergency contraceptive pills, unsafe abortion
\end{abstract}

\section{INTRODUCTION}

Emergency contraception (EC) is a method used to avoid pregnancy after unprotected sexual intercourse or a contraceptive accident to prevent an unwanted pregnancy [1]. Unintended pregnancy and unsafe abortion are the consequences of the unprotected sex and can be prevented by emergency contraceptive pills (ECPs) [2]. It is not an abortion method [1]. There are two type of EC: hormonal methods (pills) and the insertion of intrauterine device (IUD) available in Nepal. Hormonal emergency contraception pill consists of: (i) combined oral contraceptive pills- what is known as the Yuzpe regimen.

*Correspondence: Bindu Malla

Department of Clinical Pharmacology

Gandaki Medical College, Kaski, Nepal

Email:bindumalla8@ hotmail.com
It contains $0.5 \mathrm{mg}$ of Levonorgestrel plus $0.1 \mathrm{mg}$ of Ethinyl-estradiol, two doses at 12 hours' interval within 72 hours of exposure. (ii) Emergency (postcoital) pillcontains levonorgestrel $1.5 \mathrm{mg}$ single dose taken as soon as possible but before 72 hours of unprotected intercourse $[3,4]$.

Regarding the mechanism of action, EC works by preventing fertilization, implantation and tubal transportation of sperm and ovum [3]. The Intrauterine Contraceptive Device (IUCD) used for emergency contraception is the Copper T 380A IUCD (Para Gard). It can be inserted up to 5 days after unprotected sexual intercourse but should be inserted as soon as possible. The IUCD can be removed after the next menstrual period, when it is confirmed that woman is not pregnant. IUCD can use for long-term birth control. The copper IUCD can be left in place for up to 10 years for contraception, and it is a reversible form of birth control [5]. It is estimated that globally each year, approximately 210 million women 
become pregnant. Among them, about 75 million pregnancies are unplanned; 19 million unsafe abortions occurs in the developing countries and around 70,000 women die from abortion-related causes [6]. Nepal has a high incidence of unplanned pregnancies and unsafe abortion particularly among adolescents and currently married women of reproductive age (15-24 years of age.) [5]. Emergency contraception offers a final opportunity to prevent the unwanted pregnancy, reduce mortality and morbidity due to the consequences of unsafe abortion in adolescents. Adolescent pregnancy is associated with adverse maternal, fetal and neonatal outcomes [7]. Therefore, this study aimed at assessing the knowledge, attitude and practice of ECPs among medical and paramedical students.

\section{MATERIALS AND METHODS}

The study was institutional based descriptive crosssectional study design to access the knowledge, attitude and practice of ECPs among the first and second year medical and paramedical students of Gandaki medical college and The School of Health and Allied Sciences, Pokhara University. The anonymity of subjects was maintained by asking them not to write their name and students were not forced to participate in the study. Before providing questionnaire, students were consented and briefed about the purpose of the study and method of filling the questionnaire. No instruction was give during the filling up of the questionnaire. Total 30 minutes were given to fill up the questionnaire. The filled questionnaires were collected after completion of time. The study was conducted on August 2015-January 2016.The sample size for the study was 181 students among them male students were 74 and female students were 107.

\section{Data analysis}

Data were collected using questionnaires and entered Microsoft excel 2007 spreadsheet for descriptive analysis. A student's t- test was used to determine the statistical significance of difference between values for the various questions. ${ }^{\mathrm{b}} \mathrm{P}$-value $<0.05$ and ${ }^{\mathrm{c} P}$-value $<0.01$ were considered statistically significant.

\section{RESULTS}

\section{Socio-demographic Characteristics:}

Out of the total respondents of 181 students, 74 students were male and 107 students were female. Most of the male belongs to age group 20-22 and female students belong to age group 17-19. All of them were single. Likewise, 165 students were from urban residential area and 16 were from rural areas. Among them more male students were from rural area. Majority of them were Hindu (86.2\%). Most of the students belong to MBBS department $(67.4 \%)$ and least of them belong to $\mathrm{B}$. $\mathrm{Ph}$ $(2.2 \%)$ where most of the students were in their first year of undergraduate study. (Table 1)

\section{Knowledge of students' towards ECPs}

Among the total respondents of 181 students, $36.4 \%$ (30 male and 36 female) did not know about the proper time period to use ECPs after unprotected sex, whereas $63.5 \%$ (44 male and 71 female) respondent knew about the proper time of having ECPs after unprotected sex (Figure1). Among them female students are more correct than the male students.

Among 181 respondent students, 170 students heard about ECPs, 7 students hadn't heard and 4 students did not know about ECPs. Most of the students (134) knew that ECPs did not terminate the pregnancy, whereas 28 students did not know about this and 19 students were not correct. Similarly, majority of them believed that ECPs are more effective when taken immediately after unprotected sex and ECPs do not protect from sexually transmitted diseases (STD). Moreover, 135 students believed that ECPs are over the counter drug, 17 students did not know about this and 29 believed that ECPs are available only after prescription from the doctor.

\section{Attitude of students towards ECPs}

Majority of students agreed to use as well as to recommend ECPs to friends and family after unprotected sex to avoid unwanted pregnancy. $43.1 \%$ students said that wide spread use of ECPs will increase the prevalence of HIV/AIDS and other STDs, 32.0\% students disagreed and $42.1 \%$ students remained neutral. Majority of the students agreed that widespread use of ECPs promotes promiscuity $(48.1 \%)$, promote irresponsible sexual behavior $(59.1 \%)$ and increase the prevalence of HIV/AIDS and other STDs (43.1\%). Similarly, 77.3\% students agreed that ECPs should be cheaper and easily available in pharmacies. Though ECPs might affect pregnancy in future and might be harmful to the body $(53.5 \%)$, most of the students $(62.4 \%)$ believed that ECPs should be available to the victim of rape and other as well. In addition to this $46.4 \%$ students agreed that ECPs discourage the use of condom with partner. (Table 3) 
Table 1. Socio-demographic and academic characteristics of respondents

\begin{tabular}{|c|c|c|c|c|c|}
\hline \multirow{2}{*}{ CHARACTERISTICS } & & \multicolumn{2}{|c|}{ Number } & \multirow{2}{*}{ Total } & $\begin{array}{c}\text { Percent } \\
\%\end{array}$ \\
\cline { 3 - 4 } & & Male & Female & & \\
\hline \multirow{2}{*}{ Age } & $17-19$ & 27 & 82 & 109 & 60.2 \\
& $20-22$ & 46 & 25 & 71 & 39.2 \\
& $23-25$ & 1 & 0 & 1 & 0.6 \\
\hline \multirow{2}{*}{ Marital } & Single & 74 & 107 & 181 & 100.0 \\
Status & Married & 0 & 0 & 0 & 0.0 \\
\hline \multirow{2}{*}{ Residence } & Urban & 61 & 104 & 165 & 91.2 \\
Area & Rural & 13 & 3 & 16 & 8.8 \\
\hline \multirow{2}{*}{ Religion } & Hindu & 67 & 89 & 156 & 86.2 \\
& Buddhist & 5 & 7 & 12 & 6.6 \\
& Muslim & 1 & 0 & 1 & 0.6 \\
& Other & 1 & 2 & 3 & 1.7 \\
\hline \multirow{2}{*}{ Department } & MBBS & 63 & 59 & 122 & 67.4 \\
& B.Pharmacy & 9 & 19 & 28 & 15.5 \\
& B. MLT & 1 & 21 & 22 & 12.2 \\
& Bsc.Nursing & 0 & 5 & 5 & 2.8 \\
& B. Ph & 1 & 3 & 4 & 2.2 \\
\hline \multirow{2}{*}{ Year of study } & Year II & 18 & 29 & 47 & 26.0 \\
\hline
\end{tabular}

Table 2. Knowledge about ECPs among students in Gandaki medical college and the school of Health and Allied Sciences, Pokhara University.

\begin{tabular}{|c|c|c|c|c|}
\hline CHARACTERISTICS & Sex & Yes $(\%)$ & No $(\%)$ & $\begin{array}{c}\text { I don't know } \\
(\%)\end{array}$ \\
\hline \multirow[t]{3}{*}{ Have you ever heard about ECPs? } & Male & 73 (98.6) & $0^{c}(0)$ & $1^{\mathrm{c}} \quad(1.35)$ \\
\hline & Female & $97(90.7)$ & $7^{\mathrm{b}}(6.5)$ & $(2.8)$ \\
\hline & Total & $170(93.9)$ & $7(3.9)$ & $(2.2)$ \\
\hline \multirow{3}{*}{$\begin{array}{c}\text { Do ECPs terminate pregnancy if } \\
\text { woman is already pregnant? }\end{array}$} & Male & $8^{c}(10.8)$ & $59(79.7)$ & $7^{\mathrm{c}} \quad(9.45)$ \\
\hline & Female & $11^{\mathrm{b}}(10.3)$ & $75(70.1)$ & $(19.6)$ \\
\hline & Total & $19(10.5)$ & $13(74)$ & $(\mathbf{1 5 . 5})$ \\
\hline \multirow{3}{*}{$\begin{array}{l}\text { ECPs are more effective when } \\
\text { taken immediately? }\end{array}$} & Male & $55(74.3)$ & $9^{c}(12.2)$ & $10^{\mathrm{c}}(13.5)$ \\
\hline & Female & $55(51.4)$ & $13(12.1)$ & $(36.4)$ \\
\hline & Total & $110(60.8)$ & $22 \quad(12.2)$ & $(27.1)$ \\
\hline \multirow[t]{3}{*}{ Do ECPs provide protection from STD? } & Male & $7^{c}(9.5)$ & $56 \quad(75.7)$ & $11^{\mathrm{c}}(14.9)$ \\
\hline & Female & $13^{\mathrm{b}}(12.1)$ & $82 \quad(76.6)$ & $12^{\mathrm{b}} \quad(11.2)$ \\
\hline & Total & $20(11.1)$ & 138 (76.2) & $(\mathbf{1 2 . 7})$ \\
\hline \multirow[t]{3}{*}{ Are ECPs available by prescription only? } & Male & $5^{c}(6.6)$ & $62 \quad(83.8)$ & $(9.5)$ \\
\hline & Female & $24(22.4)$ & $(68.2)$ & $(9.3)$ \\
\hline & Total & $29(16.0)$ & $135 \quad(74.6)$ & $(9.4)$ \\
\hline
\end{tabular}


Table 3. Attitude towards ECPs among respondents

\begin{tabular}{|c|c|c|c|c|}
\hline OPTIONS & Sex & $\begin{array}{c}\text { Agree } \\
(\%)\end{array}$ & Neutral $(\%)$ & Disagree $(\%)$ \\
\hline If I have unintended sexual intercourse & Male & 79.7 & $13.5^{\mathrm{b}}$ & $6.8^{c}$ \\
\hline \multirow[t]{2}{*}{ I would use ECP } & Female & 86.9 & $6.6^{\mathrm{b}}$ & $1.1^{\mathrm{b}}$ \\
\hline & Total & 84.0 & 12.2 & 3.9 \\
\hline $\begin{array}{l}\text { If a close friend or relatives have unintended sexual } \\
\text { intercourse }\end{array}$ & Male & 91.9 & $6.8^{c}$ & $1.4^{\mathrm{c}}$ \\
\hline \multirow[t]{2}{*}{ I would advise to use ECP } & Female & 90.7 & $6.5^{\mathrm{b}}$ & $2.8^{\mathrm{b}}$ \\
\hline & Total & 91.2 & 6.6 & 2.2 \\
\hline \multirow{3}{*}{$\begin{array}{l}\text { Wide spread use of ECPs will increase } \\
\text { the prevalence of HIV/AIDS and other STDs }\end{array}$} & Male & 45.9 & 21.6 & 32.4 \\
\hline & Female & 41.1 & 16.0 & 31.8 \\
\hline & Total & 43.1 & 42.1 & 32.0 \\
\hline \multirow[t]{3}{*}{ Emergency contraceptive pills promote promiscuity } & Male & 52.7 & 20.3 & 27.0 \\
\hline & Female & 44.9 & 29.9 & 25.2 \\
\hline & Total & 48.1 & 26.0 & 26.0 \\
\hline \multirow{3}{*}{$\begin{array}{l}\text { If readily available, it will promote } \\
\text { irresponsible sexual behavior. }\end{array}$} & Male & 59.5 & 27.0 & $13.5^{\mathrm{b}}$ \\
\hline & Female & 58.9 & 21.5 & 19.6 \\
\hline & Total & 59.1 & 23.8 & 17.1 \\
\hline \multirow{3}{*}{$\begin{array}{l}\text { May cause more STD or HIV prevalence } \\
\text { due to seldom usage of condoms }\end{array}$} & Male & 64.9 & $16.2^{\mathrm{b}}$ & 18.9 \\
\hline & Female & 55.1 & 29.0 & 15.9 \\
\hline & Total & 59.1 & 23.8 & 17.1 \\
\hline \multirow[t]{3}{*}{ Emergency contraceptives should be easily accessible. } & Male & 68.9 & $25.7^{\mathrm{b}}$ & $5.4^{\mathrm{c}}$ \\
\hline & Female & 79.4 & $17.8^{\mathrm{b}}$ & $2.8^{\mathrm{c}}$ \\
\hline & Total & 75.1 & 21.0 & 3.9 \\
\hline \multirow[t]{3}{*}{ Emergency contraceptives should be cheaper. } & Male & 82.4 & $13.5^{\mathrm{b}}$ & $4.1^{\mathrm{c}}$ \\
\hline & Female & 73.8 & 9.9 & $5.5^{\mathrm{b}}$ \\
\hline & Total & 77.3 & 15.5 & 7.2 \\
\hline \multirow[t]{3}{*}{ ECPs should be available to victims of rape only. } & Male & 35.1 & 14.9 & 50.0 \\
\hline & Female & 16.8 & 12.1 & 71.0 \\
\hline & Total & 24.3 & 13.3 & 62.4 \\
\hline \multirow[t]{3}{*}{ ECPs discourage the use of condom with partner. } & Male & 59.5 & $16.2^{\mathrm{b}}$ & 24.3 \\
\hline & Female & 37.4 & 37.4 & 22.4 \\
\hline & Total & 46.4 & 28.7 & 23.2 \\
\hline \multirow[t]{3}{*}{ ECPs might be harmful to the body. } & Male & 56.8 & 33.8 & $9.5^{\mathrm{b}}$ \\
\hline & Female & 51.4 & 45.8 & $2.8^{\mathrm{c}}$ \\
\hline & Total & 53.6 & 40.9 & 5.5 \\
\hline
\end{tabular}


According to figure 2, out of 181 students $29.3 \%$ students felt difficulty to use ECPs due to lack of proper knowledge. Among them female students were more (25.2\%). Likewise, $42.7 \%$ students felt humiliation to get ECPs and male students felt more humiliation (32.4 $\%)$ than female students (10.3\%).Moreover, some male students felt difficulty to use ECPs due to high price (12.2 $\%)$ and not easily available of ECPs in pharmacies(5.4 $\%)$. Moreover, only 2 male and 1 female students reported to use ECP.

\section{DISCUSSION}

Although, abortion is legalized from March 2002 in Nepal, large portions of population are unaware of this fact and adolescents are being particularly vulnerable [8]. Unwanted pregnancy associated with unsafe abortion demonstrates the urgent needs of emergency contraception [9]. Emergency contraceptives pills are effective and cost effective methods that can be used after unprotected sex to avoid unwanted pregnancies.

\section{Table 4. Practice about ECPs among respondents}

\begin{tabular}{|c|c|c|}
\hline \multirow{2}{*}{ OPTIONS } & \multicolumn{2}{|c|}{ Sex } \\
& Male & Female \\
\hline Have you ever used ECPs? & $2(2.7 \%)$ & $1(0.93 \%)$ \\
\hline $\begin{array}{c}\text { Who recommend you to use ECP? } \\
\text { Male partner }\end{array}$ & $\begin{array}{c}\text { Friends } \\
2(2.7 \%)\end{array}$ & $\begin{array}{c}\text { Male partner } \\
1(0.93 \%)\end{array}$ \\
\hline $\begin{array}{c}\text { Why did you use ECP? } \\
\text { Condom broken }\end{array}$ & $2(2.7 \%)$ & $1(0.93 \%)$ \\
\hline
\end{tabular}

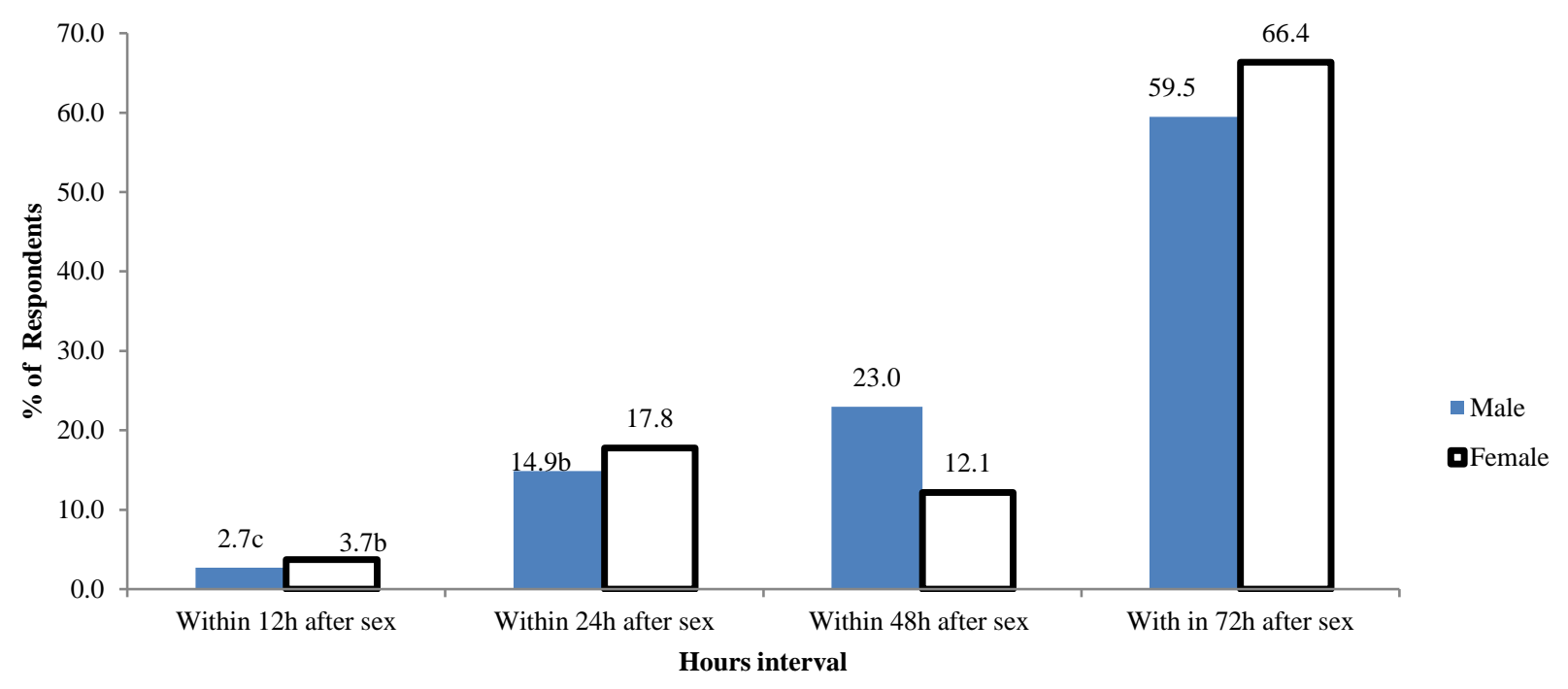

Figure 1: Knowledge about time interval to take ECPs among students in Gandaki medical college and the school of Health and Allied Sciences, Pokhara University. 


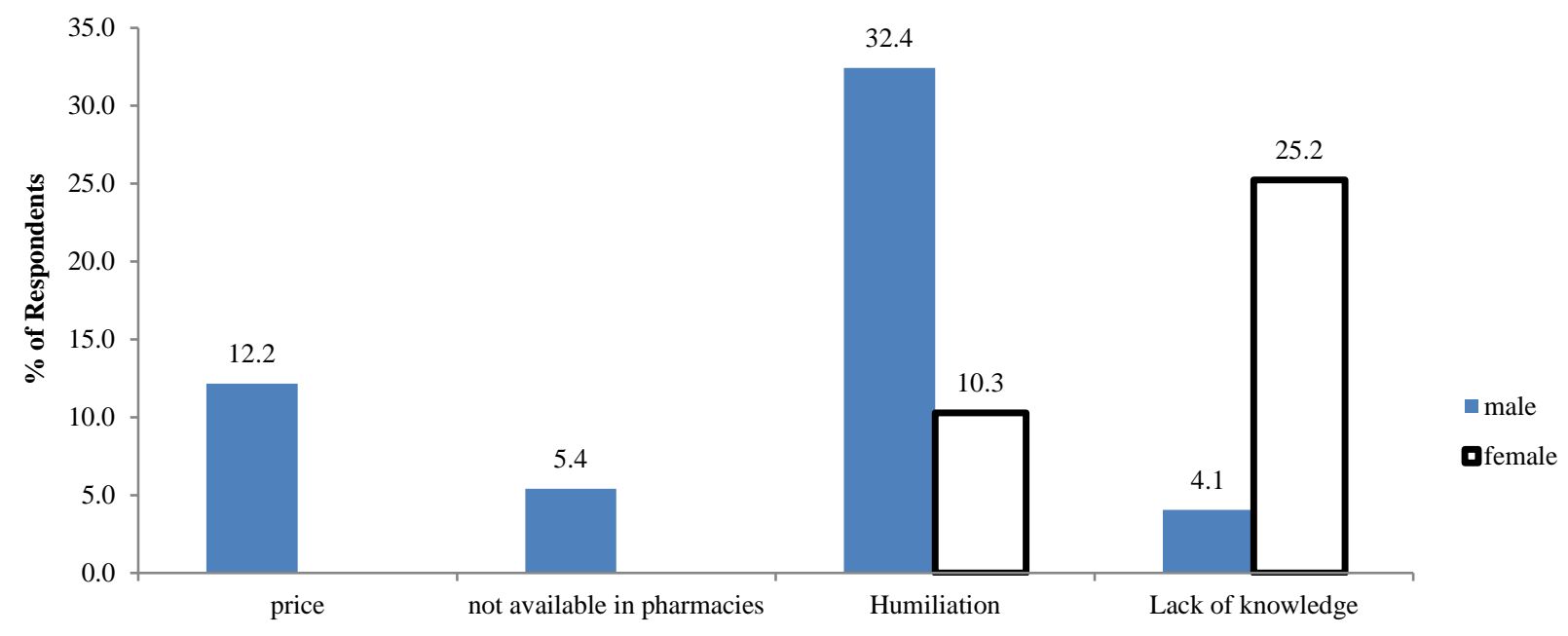

Figure. 2. Practice of ECPs among students recipients

EC is found to be effective if used as soon as possible after unprotected sexual intercourse, especially within 72 hours after intercourse, but recent studies have confirmed that theyare effective for up to 120 hours $[3,9,10,11$, 12].Thus, decrease the rate of unsafe abortion. Emergency contraception is most useful when there is a failure of barrier methods such as slippage and breakage of condoms or when sexual intercourse was unpredicted $[2$, 13].

Although ECPs are not recommended as a routine family planning method, they are very useful method after unprotected sexual intercourse to reduce the chance of unplanned or unwanted pregnancies. ECPs are effective means of preventing unwanted pregnancies, but unfortunately the large numbers of college-going students' are unaware of them [14].

This study has assessed the knowledge, attitude and utilization of contraceptive pills among the medical and paramedical students of Kaski district, Nepal. In the present study, 74 male (40.9\%) and 107 female students $(59.1 \%)$ were participated. Majority of the students were Hindu from urban area and none of them were married. As compared to female students (90.7\%) more male students $(98.7 \%)$ had heard about ECPs and among them only $66.4 \%$ female students knew the correct time to administer ECPs after unprotected sexual intercourse. However, male students had more knowledge towards ECPs than female students.
Significantly large number of male and female students agreed to use and recommend ECPs to friends and relatives to avoid unplanned pregnancy after unintended sexual intercourse. Majority of them believed that widespread use of ECPs will promote irresponsible sexual behavior, promiscuity, increase prevalence of STD and HIV due to seldom usage of condom and discourage the use of condom with partner. Despite this fact, significantly large number of students agreed that ECPs should be cheaper and easily accessible to all.

Our analysis shows that male students were likely to have more knowledge than were female students. It could be due to the fact that more males are open to talking with friends or seniors about issues of sex and sexuality than are females. Regarding the practice, male students faced more humiliation to get ECPs from pharmacy, whereas due to the lack of proper knowledge, female students faced more challenged to get ECPs. Therefore, efforts should be made by the government and relevant agencies at all levels to promote the use of ECPs especially among the adolescents and the youths who are at risk of casual sex and unwanted pregnancies [15].

Our students generally had favorable opinions about ECPs but most of them believed that ECPs have harmful effect to the body and would discourage the use of condom with partner. Similar findings have been reported by other authors $[15,16,17,18]$. The study also indicates that those respondents with poor knowledge were less likely to use EC compared to those with good knowledge [19]. 


\section{CONCLUSION}

We conclude that the knowledge about the ECPs is incomplete and misinformation is high among these students. Despite the positive attitude towards the ECPs most of them believe ECPs are unsafe for their use. Therefore, we strongly recommend that strategies to promote the correct use of ECPs should be lunched from the government and private sector as well. Information regarding the ECPs and emergency contraceptive pills should be easily accessible in pharmacies with reasonable price to students.

\section{AUTHORS' AFFILIATION}

Bindu Malla ${ }^{1}$, Komal Malla ${ }^{2}$, Madan Sigdel ${ }^{1}$, Sanjeev Guragain ${ }^{1}$, Rajesh Kumar Yadav ${ }^{1}$, Sabita Paudel ${ }^{1}$, Bijay Aryal ${ }^{1}$

${ }^{1}$ Department of Clinical Pharmacology, Gandaki Medical College, Kaski, Nepal.

${ }^{2}$ Department of Pharmacy, School of Health and Allied Sciences. Pokhara University, Lekhnath-12, Kaski, Nepal.

\section{REFERENCES}

1. Thapa B. Knowledge and attitude regarding emergency contraception among nursing personnel. JCMC. 2013; 3(3):46-50.

2. Alam K, Snover A, Sultana N, Munir TA Shah SS. Emergency contraception : knowledge, attitude and practices among doctors of a tertiary care hospital. J. Ayub Med Coll Abbottabad. 2013; 25 (1-2): 141-44.

3. Ahmed FA, Moussa KM, Petterson KO, Asamoah BO. Assessing knowledge, attitude, and practice of emergency contraception: a cross- sectional study among Ethopian undergraduate female students. BMC Public Health. 2012; 12:110. Doi: 10.1186/1471-2458-12-110.

4. Tripathi KD Essential of medical pharmacology ( $7^{\text {the }}$ ). Replika press Pvt. Ltd. New Delhi. 2013; 321-23.

5. Thapa S, Lopchan M, Mehta RK. Knowledge and attitude regarding emergency contraception among higher secondary students. JNHS. 2015; 4(3): 46-49.

6. Gebrehiwot H, Gebrekiden B, Berhe H, Kidanu K. Assessment of knowledge, attitude and practice towards emergency contraceptives among female college students at Mekelle town, Tigray region, Ethiopia: A cross sectional study. Int J Pharm Sci Res. 2013; 4(3): 1027-38.
7. Somba MJ, Mbonile M, Obure J, Mahande MJ. Sexual behavior, contraceptive knowledge and use among female undergraduates' students of Muhimbili and Dares Salaam universities Tanzania: a Cross- section study. BMC Women's Health. 2014; 14:19. Doi: 10.1186/1472-687414-94.

8. Tuladhar H, Risal A. Level of awareness about legalization of abortion in Nepal: A study at Nepal Medical College Teaching Hospital. Nepal Med Coll J. 2010; 12(2): 76-80.

9. Mandal PK, Paria B, Chakrabarty D, Roy AKS, Sau M, Mukherjee A. Emergency contraceptive pills: Perception and practice among college students in a rural area of west Bengal. Indian J. Soc. Med. 2012; 43(1): 68-71.

10. Shroff KN, Gayakwad RJ, Bavarva N, Patel F, Patal NB. Assessment of knowledge, attitudes and practices of emergency contraception among college students. Natl J Med Res. 2014; 14(2):142-44.

11. Sychareun V, Hansana V, Phengsavanh A, Phongsavan K. Awareness and attitudes towards emergency contraceptive pills among young people in the entertainment places, Vientiane city, Lao PDR. BMC Women's Health. 2013; 13:14. Doi: 10.1186/1472-687413-14.

12. Shiferaw BZ, Gashaw BT, Tesso FY. Knowledge, attitude and practice of emergency contraceptives among Mizan- Tepi university female students, South west Ethiopia. J. Pain Management Med. 2016; 2:111. Doi:10.4172/jpmme.1000111.

13. Onasoga OA, Afolayan JA, Asamabiriowei TF, Jibril UN, Imam AA. Adolescents' knowledge, attitude and utilization of emergency contraceptive pills in Nigeria's Niger Delta Region. IJMA. 2016; 5 (1): 53-60.

14. Adhakari R. Factors affecting awareness of emergency contraception among college students in Kathmandu, Nepal. BMC Women's Health. 2009; 9:27. Doi: 1472-6874-9-27-SI.

15. Ojule JD, Oriji VK, Georgewill KN. Awareness and practice of emergency contraception among students of university of Port Harcourt, South-South Nigeria. TNHJ. 2008; 8(1-2): 6-9.

16. KassaA,Wolde-Mariam M. Knowledge, attitude and practice of emergency contraceptive pills among female 
students of Hosanna College of Health Sciences, Hosanna, South Ethiopia. JCPS. 2014; 7(3):185-93.

17. Kongnyuy EJ, Ngassa P, Fomulu N, Wiysonge CS, Kouam L, Doh AS. A survey of knowledge, attitudes and practice of emergency contraception among university students in Cameroon. BMC Emerg Med. 2007; 7:7. Doi: $10.1186 / 1471-227 \times-7-7$.

18.Girma T, Ejeta E, Dechasa A, Abdulkadir K. Knowledge, attitude and practices of emergency contraception among female students in preparatory school of East Shoa, Adama, Ethopia. Gynecol Obstet. 2015; 5:8. Doi:10.4172/2161-0932.1000310.

19. Abate M, Assefa N, Alemayehu T. Knowledge, attitude, practice and determinants emergency contraceptive use among women seeking abortion services in Dire Dawa, Ethopia. PLoS ONE. 2014; 9 (10). Doi: 10.1371/journal.pone.0110008.

\section{Article History:}

Received: $7^{\text {th }}$ December, 2016

Accepted: 23 March, 2017

Published online: 19 July

\section{For Citation:}

Malla B et al. Assessment of Knowledge, Attitude and Practice of Emergency Contraceptive Pills among Medical and Paramedical Students. International Journal of Medicine \& Biomedical Sciences. 2017; 2(2):6-13 